\title{
Empathy and emotion recognition in semantic dementia: A case report
}

\author{
Marco Calabria a , Maria Cotelli ${ }^{\mathrm{a}, *}$, Mauro Adenzato ${ }^{\mathrm{b}, \mathrm{c}}$, Orazio Zanetti ${ }^{\mathrm{a}}$, Carlo Miniussi ${ }^{\mathrm{a}, \mathrm{d}}$ \\ a IRCCS San Giovanni di Dio - Fatebenefratelli, Via Piastroni, 425125 Brescia, Italy \\ ${ }^{\mathrm{b}}$ Center for Cognitive Science, Department of Psychology, University of Turin, Italy \\ ${ }^{\mathrm{c}}$ Neuroscience Institute of Turin, Italy \\ ${ }^{\mathrm{d}}$ Department of Biomedical Sciences and Biotechnologies, Physiology Section and National Institute of Neuroscience-Italy, University of Brescia, Italy
}

\section{A R T I C L E I N F O}

\section{Article history:}

Accepted 19 February 2009

Available online 31 March 2009

\section{Keywords:}

Empathy

Facial expression

Emotional processing

Semantic dementia

\begin{abstract}
A B S T R A C T
Recent studies have demonstrated that patients suffering from frontotemporal lobar degeneration (FTLD) show impairments in empathy and emotional processing. In this study, we examined two different aspects of these abilities in a patient with semantic dementia (SD), a variant of FTLD. The first aspect was the assessment of the cognitive and emotional components of empathy through the Interpersonal Reactivity Index. The second was the naming and comprehension of emotions using the Ekman 60 Faces Test. The patient's emotion word knowledge was spared and the emotional aspects of empathy preserved. Conversely, the patient performed below average for all of the basic emotions when an emotion word had to be matched with a picture. When picture-to-picture matching was tested, however, the patient was able to recognize happiness. This case is a good example of a dissociation of covert and overt emotional functioning in SD. Results are discussed in terms of the impaired empathic behavior and emotional functioning in FTLD.
\end{abstract}

(c) 2009 Elsevier Inc. All rights reserved.

\section{Introduction}

Frontotemporal lobar degeneration (FTLD) is a neurodegenerative disorder predominantly affecting the frontal and temporal lobes, presenting with prominent behavioral and personality changes as well as cognitive impairment. Diagnostic criteria for FTLD agree that alteration in personality and social conduct are central clinical features of the disease (Brun et al., 1994; Cairns et al., 2007; Neary et al., 1998). This disease is a syndrome that encompasses a spectrum of clinical variants: frontal or behavioral variants (fv-FTD), language variants (the temporal variant or semantic dementia (SD) and non-fluent progressive aphasia (NFPA)) and motor variants (corticobasal degeneration and motor neuron disease) (McKhann et al., 2001; Neary et al., 1998). Patients with FTLD are characterized by marked changes in behavior and personality from the onset of the disease onwards (Brun et al., 1994; Wittenberg et al., 2008). In particular, loss of empathy and emotion recognition disturbances are central symptoms of FTLD (Gorno-Tempini et al., 2004b; Kipps \& Hodges, 2006; Lough et al., 2006; Viskontas, Possin, \& Miller, 2007).

Empathy is the ability to share the emotions and sensations of others (Lieberman, 2007; Singer, 2006). It is often characterized as the ability to "put oneself into another's shoes", or in some way experience another person's emotions within oneself. The

\footnotetext{
* Corresponding author. Fax: +39 0303501513.

E-mail address: mcotelli@fatebenefratelli.it (M. Cotelli).
}

absence of empathy might also be related to an absence of Theory of Mind, i.e., the ability to explain and predict other people's behavior by attributing independent mental states to them (Baron-Cohen, 1995; Becchio, Adenzato, \& Bara, 2006; Premack \& Woodruff, 1978). These abilities are crucial for a higher social functioning, and when impaired, difficulty with social conduct is observed. These symptoms are observed in FTLD patients.

The relationship among empathy, emotions and behavioral disturbances has been investigated in different ways (Lough et al., 2006). Rankin, Kramer, Mychack, and Miller (2003) used the Interpersonal Adjective Scales (IAS, Wiggins, 1995), a self- and otherreport questionnaire based on a personality theory of interpersonal constructs, in a group of FTLD patients. They found that SD patients present with severe interpersonal coldness, whereas fv-FTD patients shift toward the opposite pattern.

In a successive study, Rankin, Kramer, and Miller (2005) investigated empathic behavior in greater depth. In a group of FTLD patients, they used the Interpersonal Reactivity Index (IRI; Davis, 1983), a questionnaire that measures the different aspects of empathy. They found that SD patients were impaired in the emotional and cognitive components of empathy, whereas fv-FTD patients showed only disruption of the cognitive components. This difference was due to the different neuronal networks involved. Rankin et al. (2006) found that the empathy score was positively correlated with the volume of the right temporal structures in SD patients, suggesting that these areas play a major role in social conduct.

Other studies have investigated emotional functioning through facial expressions. One of the first studies carried out by Lavenu, 
Pasquier, Lebert, Petit, and Van der Linden (1999) described a group of FTLD patients who performed worse than Alzheimer's disease (AD) patients in naming of emotions and in recognition of anger, sadness and disgust. In this respect, several studies have reported that negative emotions are more difficult for FTLD patients to recognize than positive emotions (Diehl-Schmid et al., 2007; Fernandez-Duque \& Black, 2005; Keane, Calder, Hodges, \& Young, 2002).

The neural damage in SD and fv-FTD patients is qualitatively different. As a result, the pattern of cognitive deficits is also different. In particular, voxel-based morphometry (VBM) studies have shown that SD is characterized by anterior temporal lobe atrophy (Gorno-Tempini, et al., 2004a; Patterson, Nestor, \& Rogers, 2007), whereas frontal lobe degeneration is prevalent in fv-FTD patients. Cognitively, SD is characterized by speech output and word comprehension deficits (Snowden, Goulding, \& Neary, 1989) with a relative sparing of phonology and grammar (Hodges \& Patterson, 2007). Patients with fv-FTD, however, show more prominent impairment in dysexecutive functions (Harciarek \& Jodzio, 2005; Hutchinson \& Mathias, 2007; Perry \& Hodges, 2000).

Rosen et al. (2004) compared groups of fv-FTD and SD patients, finding that both groups had a decreased performance compared to healthy controls in matching, naming and discriminating negative facial expressions. Nevertheless, SD patients were not impaired in recognition of happiness (see also Rosen et al., 2002) in comparison to fv-FTD patients (Rosen et al., 2004).

To study empathic behavior, emotion recognition and their relationship in SD, we present a case report exploring: (1) the cognitive and emotional components of empathy through the IRI (Davis, 1983 ) and the emotion word knowledge questionnaire (Werner et al., 2007) and (2) the emotional functioning through facial expression recognition by means of the standard Ekman 60 Faces Test. A modified version of this test was also used, in which the patient was required to make picture-picture matches instead of a picture-word matches. This allowed us to avoid any confounding effect related to the language impairment.

\section{Methods}

\subsection{Case report}

The patient (CMR) was a right-handed, 67-year-old female with 8 years of education. She was recruited at the San Giovanni di Dio Fatebenefratelli Scientific Institute in Brescia, Italy.
The patient was diagnosed with SD, a language variant of FTLD, according to published criteria (McKhann et al., 2001; Neary et al., 1998). She was characterized by a prominent comprehension disorder (impaired understanding of word meaning and/or object identity) and naming difficulties. The patient had been regularly examined for at least 1.5 years, and the initial diagnosis was confirmed at follow-up. Spontaneous speech was fluent and characterized by semantic errors and anomia, without disturbances in articulation. The patient underwent a detailed clinical and neurological evaluation. Upper limb apraxia was evaluated by using a movement imitation test (De Renzi, Motti, \& Nichelli, 1980). Routine laboratory tests, including thyroid hormone dosage, vitamin B12, and serum folate and syphilic serology, were evaluated. The patient did not have potentially confounding neurological or psychiatric disorders, hearing or vision impairment, or a past history of alcohol abuse, psychosis or major depression.

The patient underwent a structural brain MRI, and visual ratings of MRI images were compatible with the clinical diagnosis. The MRI scan detected a left temporal lobe atrophy with consequent enlargement of ventricles associated with signal abnormalities within the right inferior parietal cortex (see Fig. 1).

\subsection{General neuropsychological and behavioral assessment}

Extensive neuropsychological assessment was performed, including tests for global functioning, learning and memory, nonverbal reasoning, language, as well as visuospatial and visuoperceptual, attentional, executive and praxis functioning.

The patient had a score of 26/30 on the Mini Mental State Examination (Folstein, Folstein, \& McHugh, 1975), retrieving three out of three items on the delayed recall test. Detailed neuropsychological testing showed long-term memory and language impairments and difficulties in recognition of famous faces, whereas visuospatial, perceptual and praxis abilities were spared. The results of the baseline cognitive assessment are reported in Table 1.

Language functions, such as repetition, naming, reading, writing and comprehension, were formally assessed with the full Italian version of the Aachener Aphasia Test (AAT) (Luzzatti et al., 1994). Picture naming was assessed using the Batteria per l'Analisi dei Deficit Afasici (BADA; Miceli, Laudanna, Burani, \& Capasso, 1994), an action and object-naming task for aphasia. Formal speech evaluation demonstrated normal motor speech, reading and writing skills, but a marked deficit in word retrieval and sentences compre-

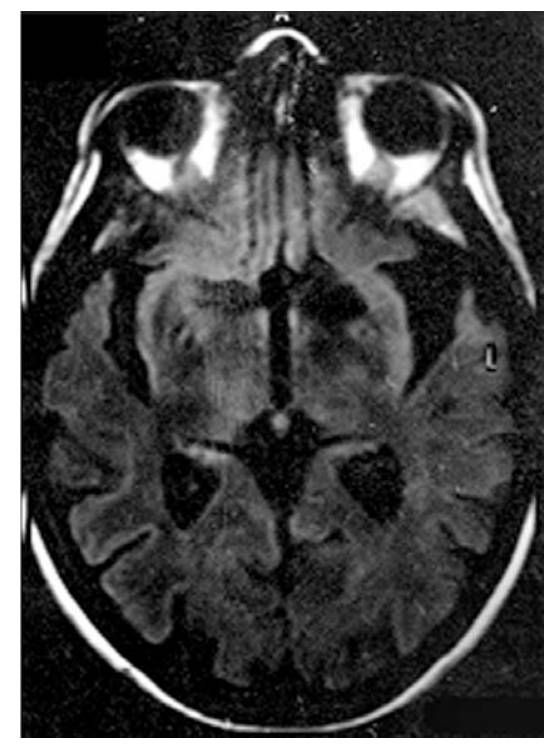

Fig. 1. A coronal and horizontal section of the MRI showing temporal atrophy (greater on the left). 
Table 1

Neuropsychological assessment.

\begin{tabular}{|c|c|c|c|}
\hline & Raw scores & Adjusted scores & Cut-off \\
\hline (A) & & & \\
\hline Mini mental state examination & $26 / 30$ & 24 & 24 \\
\hline $\begin{array}{l}\text { Non verbal reasoning } \\
\text { Raven Colored Progressive Matrices }\end{array}$ & $21 / 36$ & 23.5 & 18 \\
\hline $\begin{array}{l}\text { Long-term memory } \\
\text { Rey auditory-verbal learning test-immediate recall } \\
\text { Rey auditory-verbal learning test-delayed recall } \\
\text { Rey-sterrieth complex figure-recall }\end{array}$ & $\begin{array}{l}13 / 75^{*} \\
4 / 15 \\
0 / 36^{*}\end{array}$ & $\begin{array}{l}17 \\
5.3 \\
0\end{array}$ & $\begin{array}{l}28.52 \\
4.68 \\
9.47\end{array}$ \\
\hline $\begin{array}{l}\text { Short-term memory } \\
\text { Digit span } \\
\text { Spatial span }\end{array}$ & $\begin{array}{l}4 \\
5\end{array}$ & $\begin{array}{l}4.25 \\
5,25\end{array}$ & $\begin{array}{l}3.75 \\
3.75\end{array}$ \\
\hline $\begin{array}{l}\text { Language } \\
\text { Controlled association letters test } \\
\text { Controlled association categories test }\end{array}$ & $1^{*}$ & $\begin{array}{l}5 \\
7\end{array}$ & $\begin{array}{l}17 \\
25\end{array}$ \\
\hline $\begin{array}{l}\text { Praxis } \\
\text { Buccofacial apraxia } \\
\text { Ideomotor apraxia - right upper limb } \\
\text { Ideomotor apraxia - left upper limb } \\
\text { Rey figure -opy }\end{array}$ & $\begin{array}{l}19 / 20 \\
67 / 72 \\
69 / 72 \\
31 / 36\end{array}$ & 32.5 & $\begin{array}{l}18 \\
62 \\
62 \\
28.88\end{array}$ \\
\hline $\begin{array}{l}\text { Attentional and executive functions } \\
\text { Trial making test A } \\
\text { Trial making test B }\end{array}$ & $\begin{array}{l}56 \\
321\end{array}$ & $\begin{array}{l}36 \\
253\end{array}$ & $\begin{array}{l}93 \\
282\end{array}$ \\
\hline Aphasic battery for analysis of aphasic deficits (BADA) & & & Cut-off \\
\hline $\begin{array}{l}\text { (B) } \\
\text { Oral object naming } \\
\text { Oral action naming }\end{array}$ & $\begin{array}{l}6 / 30^{*} \\
12 / 28^{*}\end{array}$ & & $\begin{array}{l}28 \\
26\end{array}$ \\
\hline Aachener aphasie test (AAT) & & T score & Cut-off \\
\hline $\begin{array}{l}\text { Token Test } \\
\text { Ripetition } \\
\text { Writing } \\
\text { Naming } \\
\text { Comprehension }\end{array}$ & $\begin{array}{l}15 / 50^{*} \\
144 / 150 \\
88 / 90 \\
82 / 120^{*} \\
74 / 120^{*}\end{array}$ & $\begin{array}{l}56 \\
65 \\
71 \\
52 \\
45\end{array}$ & $\begin{array}{l}<7 \\
142 \\
81 \\
104 \\
108\end{array}$ \\
\hline The visual object and space perception battery (VOSP) & Raw score & & Cut-off \\
\hline $\begin{array}{l}\text { (C) } \\
\text { Incomplete letters } \\
\text { Silhouettes } \\
\text { Object recognition } \\
\text { Progressive silhouettes } \\
\text { Dot counting } \\
\text { Position discrimination } \\
\text { Number location } \\
\text { Cube analysis } \\
\text { Facial recognition test }\end{array}$ & & $\begin{array}{l}17 / 20 \\
7 / 30^{*} \\
13 / 20^{*} \\
14 / 20 \\
10 / 20 \\
19 / 20 \\
10 / 10 \\
8 / 10 \\
39 / 54\end{array}$ & $\begin{array}{l}15 \\
16 \\
17 \\
<15 \\
8 \\
18 \\
7 \\
6 \\
38\end{array}$ \\
\hline Recognition of famous faces & & Adjusted scores & \\
\hline $\begin{array}{l}\text { Fame judgement on picture presentation } \\
\text { Semantic knowledge of famous people } \\
\text { Naming of famous people on picture presentation }\end{array}$ & $\begin{array}{l}4 / 50 \\
7.75 / 50^{*} \\
0 / 50^{*}\end{array}$ & $\begin{array}{l}4 \\
12.5 \\
0\end{array}$ & $\begin{array}{l}12.90 \\
22.17 \\
14.50\end{array}$ \\
\hline Recognition of famous names & $2193.5^{*}$ & 2257.96 & 6666.46 \\
\hline
\end{tabular}

* Raw scores indicate that the patient's performance is below cut-off.

hension. Auditory verbal comprehension in a conversation setting was normal. In the Token test of the AAT, however, auditory verbal comprehension was preserved for simple commands (see Table 1, panel B).

The spontaneous speech of the patient was fluent with normal articulation without jargon output and echolalia. Repetition, reading and writing were spared. Picture naming was severely impaired. The patient produced the correct response to 6/30 objects (20\%) and to $12 / 28$ actions (43\%) in an oral naming task. Incorrect responses resulted from semantically related responses, semantic circumlocutions or anomia.

Nonverbal cognitive tests did not reveal buccofacial, ideomotor or constructive apraxia.
A detail assessment of visuoperceptual abilities was performed (see Table 1, panel C). The patient had normal performance on basic visuoperceptual abilities assessed with The Visual Object and Space Perception (VOSP) (James \& Warrington, 1991). She performed poorly on only the silhouettes and object recognition subtests. It is important to note that the pathological scores in these two latter subtests could be biased by the language deficits.

On the facial recognition test (Benton, Sivan, Hamsher, Varney, \& Spreen, 1990), which required the patient to match unfamiliar faces, the patient obtained a borderline score (39 out of 54 correct responses, cut-off score 38 ).

The patient's performance was unimpaired on the gender judgement task. In this task, a set of 64 pictures portraying unfamiliar male 
and female faces were used. Half of the faces depicted all the facial features, the other half were without external features (e.g., no hair). Stimuli were presented on the monitor of a Computer and remained on the screen until a response was made. The patient performed this task perfectly ( $100 \%$ of correct responses).

On the recognition of famous faces task (Rizzo, Venneri, \& Papagno, 2002), the patient failed to retrieve semantic knowledge and naming of famous people upon picture presentation. In this test, half of the pictures were of famous faces and the other half were unfamiliar faces. Pictures were presented and the patient was required to recognize the famous faces, provide semantic knowledge and name them. In the fame judgement subtest, the patient correctly recognized 18 out of 50 famous faces.

Finally, on the recognition of famous names task (Bizzozero, Lucchelli, Pozzoli, Saetti, \& Spinnler, 2007), which required the patient to recognize famous names printed on a sheet, half of the names were of famous people and the other half were unfamiliar. In this task, the patient performed below cut-off levels.

In summary, the patient showed a fluent progressive aphasia with naming and comprehension difficulties, a loss of verbal and nonverbal semantic knowledge about objects, concepts, people, meaning of words and recognition of famous faces.

In addition, behavioral and social changes were assessed with the Frontal Behavioral Inventory (FBI: Kertesz, Davidson, \& Fox, 1997), a caregiver questionnaire designed to operationalize and quantify the personality and behavior changes in FTLD. The FBI is a 24-item scale, composed of two subscales for negative (FBI-A) or positive behaviors (FBI-B). The patient showed clear pathological behavioral changes due to the disease (raw score of the Italian version of FBI = 36; Alberici et al., 2007). In particular, she showed apathy, indifference, disorganization, inattention, logopenia and semantic anomia (FBI-A) as well as irritability, impulsivity, aggression and hyperorality (FBI-B).

\subsection{Empathy and emotion recognition tasks}

\subsubsection{Interpersonal Reactivity Index}

The Interpersonal Reactivity Index (IRI; Davis, 1983) is a 28item questionnaire consisting of four 7-item subscales that measure both the cognitive and the emotional components of empathy. The four subscales are: (1) perspective taking (PT), i.e., the ability to adopt the viewpoint of others in everyday life, (2) fantasy (FS), i.e., the tendency to project oneself into the place of fictional characters, (3) empathic concern (EC), i.e., the feelings of sympathy and concern for people involved in unpleasant experiences and (4) personal distress (PD), i.e., the distress that results from witnessing another's negative emotional state. The PT and FS subscales measure the cognitive aspects of empathy, while subscales EC and PD measure the emotional aspects. In this study, we used an IRI questionnaire that was validated on the Italian population (Albiero, Ingoglia, \& Lo Coco, 2006). In order to assess the changes over time in the patient's empathy, we asked her daughter and husband to indicate how well each item described the patient both currently and prior to the onset of the disease using a five-point scale.

\subsubsection{Emotion word knowledge questionnaire}

As shown by the neuropsychological assessment, the patient presented with a degradation of semantic knowledge that could also involve emotion word knowledge. We investigated the integrity of such knowledge with an adapted version of the emotion word knowledge questionnaire proposed by Werner et al. (2007). This questionnaire investigates the knowledge of emotion terms by asking the patient to answer the following questions that are based on ecological situations: "How would you feel if..." (1) someone steals your wallet? (anger), (2) you smell dog poo? (disgust), (3) a man points a gun at your head? (fear), (4) a new grandchild born? (happi- ness), (5) your good friend dies? (sadness) and (6) something unexpected happens? (surprise). For each question, the patient had to choose an answer from the list of six basic emotion terms.

\subsubsection{The standard Ekman 60 Faces Test}

The Ekman 60 Faces Test uses a range of faces to test the recognition of six basic emotions (anger, disgust, fear, happiness, sadness and surprise). In this test, photographs of the faces of 10 models (six female and four male) selected from the Ekman and Friesen (1976) series are presented. For each model, there are poses corresponding to each of six basic emotions. Each face is presented on an A4 sheet with six labels of basic emotions below the photograph. The patient was required to respond verbally, deciding the label that best described the facial expression shown. The maximum score was 10 for each basic emotion (for a total score of 60 ).

\subsubsection{The modified Ekman 60 Faces Test}

In order to exclude any verbal bias in the patient's responses, we used a modified version of the Ekman 60 Faces Test. The same photographs of the standard version were used but, instead of verbal labels, another six photographs displaying the six possible basic emotions were presented below the target stimulus (always three female and three male). The patient was required to choose the photograph that matched the target stimulus, and was assessed in this version a week after the original version.

\section{Results}

\subsection{Interpersonal Reactivity Index}

In a preliminary analysis, the scores of the patient's daughter and husband were compared using the Mann-Whitney U test. No difference was found in any of the subscales. Thus, their scores were added together.

We used the Wilcoxon signed rank test to compare scores of past and current empathy status. Significant differences were found in both the PT (score: before $=54$, current $=34$ ) and FS (score: before $=43$, current $=31)$ subscales $(z=2.198, p=0.028$ and $z=$ $1.968, p=0.049$, respectively). No significant differences were found in the EC (score: before $=46$, current $=40$ ) and PD (score: before $=51$, current $=42$ ) subscales. The total score comparison was significant (before $=194$, current $=147 ; z=3.122, p=0.002$ ).

In order to evaluate the patient's performance in the two components of empathy (cognitive and emotional) predicted by Davis (1983), the PT and FS subscales were summed together in a further analysis to provide a total cognitive empathy score and EC and PD were summed together to provide a total emotional empathy score. A significant difference was found for the cognitive component (score: before $=97$, current $=65 ; z=2.948, p=0.003$ ). No difference was found in the emotional component between the preand post-disease condition (score: before $=97$, current $=82$ ). For details, see Table 2 .

\section{Table 2}

Current and prior to disease onset IRI scores with differences.

\begin{tabular}{llll}
\hline & Before & Current & Differences \\
\hline Perspective taking (PT) $^{*}$ & 54 & 34 & -20 \\
Fantasy (FS) $^{*}$ & 43 & 31 & -12 \\
Cognitive aspects of empathy $^{*}$ & 97 & 65 & $-\mathbf{3 2}$ \\
Empathic concern (EC) & 46 & 40 & -6 \\
Personal distress (PD) & 51 & 42 & -9 \\
Emotional aspects of empathy & 97 & 82 & $-\mathbf{1 5}$ \\
Total score & $\mathbf{1 9 4}$ & $\mathbf{1 4 7}$ & -47 \\
\hline
\end{tabular}

Score before and current statistically different $(p<0.05)$. 
Table 3

Correct responses for each basic emotion in the standard and modified version of the Ekman 60 Faces test. Scores marked in bold type are above the cut-off.

\begin{tabular}{lllllll}
\hline & Anger & Disgust & Fear & Happiness & Sadness & Surprise \\
\hline $\begin{array}{llllll}\text { Ekman 60 Faces } \\
\text { Patient CMR }\end{array}$ & 3 & 2 & 1 & 4 & 3 & 4 \\
$\begin{array}{l}\text { Modified Ekman } \\
\text { Patient CMR Faces }\end{array}$ & 3 & 4 & $\mathbf{4}$ & $\mathbf{1 0}$ & 0 & 4 \\
Cut-off & 4 & 6 & 3 & 9 & 5 & 6 \\
\hline
\end{tabular}

\subsection{Emotion word knowledge questionnaire}

The patient consistently reported the correct emotion required to be matched by the questions (emotion word knowledge questionnaire score $=6 / 6$ correct responses).

\subsection{The Ekman 60 Faces Test (standard and modified version)}

Table 3 describes the patient's results to the standard and to the modified version of the Ekman 60 Faces Test. These results were compared to the cut-off for the healthy population between 61 and 70 years old reported in the Facial Expressions of Emotion Stimuli and Tests manual (Young, Perrett, Calder, Sprengelmeyer, \& Ekman, 2002). In the standard version (i.e., with six labels of basic emotions below each photograph), the patient's performance was below the cut-off for all basic emotions.

In the modified version (i.e., with six faces displaying the six basic emotions below the target stimulus), the performance improved. The patient correctly matched all faces depicting happy emotions (100\%), whereas she performed poorly on all other basic emotions, especially for sadness ( $0 \%$ of correct responses). Fear was recognized above the cut-off when the cut-off of the standard version of the Ekman 60 Faces Test was taken into account. The recognition of the other basic emotions (anger, disgust, sadness and surprise) was impaired as well.

To verify statistical differences along the distribution of the proportion of correct responses for the modified version, a $\chi^{2}$ analysis was performed. The analysis showed that performance for happiness was significantly different from those of the other facial expressions $\left(\chi^{2}(5)=12.68, p=0.03\right)$.

\section{Discussion}

In the present study, we have described empathy and emotional processing in a patient with SD. Empathic behavior was investigated for its cognitive and emotional components, and emotional processing was studied through facial expressions. The primary finding of this study was that the cognitive component, but not the emotional component, was affected by the disease.

Empathy is an ability underlying the social interaction and the comprehension of the viewpoint of others in everyday life. Comparing the scores of past and current empathy status, we found significant differences in both the PT and FS subscales but no significant differences in the EC and PD subscales of the Interpersonal Reactivity Index (IRI). A further analysis, in which the subscales were collapsed in order to evaluate the patient's performance in the two components (cognitive and emotional), showed a significant difference for the cognitive component between the pre- and post-disease condition. Interestingly, these differences were not observed for the emotional component.

This unexpected finding could be explained in terms of the neuronal networks involved. In our patient, the atrophy was prevalent in the left hemisphere, whereas SD patients in the study reported by Rankin et al. (2005) had more bilateral temporal atrophy. In a voxel-based morphometry study, Rankin et al. (2006) showed that empathy scores in SD patients correlated with right temporal lobe atrophy. The authors found out that SD patients were impaired in both the emotional and cognitive aspects of empathy. It is therefore possible that the emotional aspects of empathy are more localized in the right hemisphere than in the left.

With regard to emotional recognition processing, the patient's performance was consistent with previous data published in literature (Lavenu \& Pasquier, 2005; Lavenu et al., 1999; Rosen et al., 2002, 2004, 2006). In the standard version of the Ekman 60 Faces Test, the patient scored below cut-off for all basic emotions, indicating that emotional recognition was impaired.

In a picture-picture matching task (i.e., the modified version of the Ekman 60 Faces Test), our patient performed well in the recognition of happiness. This may be due to two main reasons: happiness is easier to recognize than negative emotions (i.e., Sullivan \& Ruffman, 2004) or because recognition of happiness is processed by a neuronal network (including the amygdala and orbitofrontal cortex; Rosen et al., 2002) that is not affected in our patient. But this result, however, also suggests that the recognition of emotions, especially those that are negative, is independent of the language impairment, which is the core deficit in SD pathology. Face matching tasks were frequently used in the literature but, to our knowledge, the concomitant use of the standard and the modified version of the Ekman 60 Faces Test was employed here for the first time. A recent study by Diehl-Schmid et al. (2007) applied the classical version of the Ekman 60 Faces Test and showed that it is a good discrimination tool for FTLD diagnosis. Patients with FTLD scored significantly lower compared to healthy controls and below cutoff in recognition for all emotions except for happiness.

Several studies have employed nonverbal tasks in facial expression recognition in FTLD patients, but detailed results regarding all the basic emotions were not reported. Rosen et al. (2002), for example, showed that SD patients performed worse than controls when they were required to name emotions from faces. Furthermore, they also performed worse when selecting the correct facial expressions among a series of photographs and in a picture-picture matching task. Overall, only happiness was correctly recognized. The authors, however, did not report the presence of any other differences among the emotions between the two tasks. In a successive study, Rosen et al. (2004) confirmed the same results in a group of SD patients compared to a group of fv-FTD patients.

Another issue raised from our findings concerns the dissociation between defective language comprehension and emotion knowledge. Our patient reported the appropriate emotional status in the questionnaire of emotional word knowledge (adapted from Werner et al., 2007). This means that her knowledge regarding emotion terms was preserved, excluding any hypothesis of a defect in comprehension.

Taken together, emotional reactivity per se persists in our patient, but the cognitive mechanisms involved in the interpretation of emotion are no longer available. This is consistent with a recent study by Werner et al. (2007), who showed that FTLD patients (fvFTD and SD) had a preserved capacity to feel emotions and showed physiological reactivity in response to emotional films. More interestingly, in the study by Werner et al. (2007) their SD patients were capable of recognizing fear in film clips, whereas fv-FTD showed poor recognition. This is consistent with our patient's ability to recognize fear in the modified version of the Ekman 60 Faces Test.

These results indicate that our patient is still able to feel emotions (due to the spared emotional component of empathy), even though the overt recognition is dramatically impaired. This interesting data could explain why the behavioral disturbances in the social conduct are very common in SD patients from the onset of the disease. These patients can experience the emotions, but the impaired cognitive recognition prevents them from executing a 
congruent behavioral response. This also suggests that the assessment of these abilities in SD patients could have clinical significance in improving the diagnosis.

\section{Acknowledgments}

Marco Calabria was supported by Associazione Fatebenefratelli per la Ricerca (AFaR) fundings. Mauro Adenzato was supported by Regione Piemonte fundings (Bando regionale per la ricerca scientifica 2004, cod. A239).

\section{References}

Alberici, A., Geroldi, C., Cotelli, M., Adorni, A., Calabria, M., Rossi, G., et al. (2007). The frontal behavioural inventory (Italian version) differentiates frontotemporal lobar degeneration variants from Alzheimer's disease. Neurological Science, 28(2), 80-86.

Albiero, P., Ingoglia, S., \& Lo Coco, A. (2006). Contributo all'adattamento italiano dell'Interpersonal Reactivity Index [A contribution to the Italian validation of the Interpersonal Reactivity Index]. Testing Psicometria Metodologia, 13, $107-125$.

Baron-Cohen, S. (1995). Mindblindness: An essay on autism and theory of mind. Cambridge: MIT Press.

Becchio, C., Adenzato, M., \& Bara, B. G. (2006). How the brain understands intention: Different neural circuits identify the componential features of motor and prior intentions. Consciousness and Cognition, 15, 64-74.

Benton, A. L., Sivan, A. B., Hamsher, K. de S., Varney, N. R., \& Spreen, O. (1990). Test di Riconoscimento di volti (facial recognition). Firenze, Italy: Organizzazioni Speciali.

Bizzozero, I., Lucchelli, F., Pozzoli, S., Saetti, M. C., \& Spinnler, H. (2007). What do you know about Ho Chi Minh? Italian norms of proper name comprehension. Neurological Science, 28(1), 16-30.

Brun, A., Englund, B., Gustafson, L., Passant, U., Mann, M. D. A., \& Snowden, J. S. (1994). Clinical and neuropathological criteria for frontotemporal dementia. Journal of Neurology Neurosurgery and Psychiatry, 57, 416-418.

Cairns, N. J., Bigio, E. H., Mackenzie, I. R., Neumann, M., Lee, V. M., Hatanpaa, K. J., et al. (2007). Neuropathologic diagnostic and nosologic criteria for frontotemporal lobar degeneration: Consensus of the consortium for frontotemporal lobar degeneration. Acta Neuropathologica, 114(1), 5-22.

Davis, M. H. (1983). Measuring individual differences in empathy: Evidence for a multidimensional approach. Journal of Personality and Social Psychology, 44, $113-126$.

De Renzi, E., Motti, F., \& Nichelli, P. (1980). Imitating gestures. A quantitative approach to ideomotor apraxia. Archives of Neurology, 37(1), 6-10.

Diehl-Schmid, J., Pohl, C., Ruprecht, C., Wagenpfeil, S., Foerstl, H., \& Kurz, A. (2007). The Ekman 60 Faces Test as a diagnostic instrument in frontotemporal dementia. Archives of Clinical Neuropsychology, 22(4), 459-464.

Ekman, P., \& Friesen, W. (1976). Pictures of facial affect. Palo Alto, CA: Consulting Psychologist Press.

Fernandez-Duque, D., \& Black, S. E. (2005). Impaired recognition of negative facial emotions in patients with frontotemporal dementia. Neuropsychologia, 43(11), 1673-1687.

Folstein, M. F., Folstein, S. E., \& McHugh, P. R. (1975). “Mini-mental state”. A practical method for grading the cognitive state of patients for the clinician. Journal of Psychiatric Research, 12(3), 189-198.

Gorno-Tempini, M. L., Dronkers, N. F., Rankin, K. P., Ogar, J. M., Phengrasamy, L., Rosen, H. J., et al. (2004a). Cognition and anatomy in three variants of primary progressive aphasia. Annals of Neurology, 55(3), 335-346.

Gorno-Tempini, M. L., Rankin, K. P., Woolley, J. D., Rosen, H. J., Phengrasamy, L., \& Miller, B. L. (2004b). Cognitive and behavioral profile in a case of right anterior temporal lobe neurodegeneration. Cortex, 40(4-5), 631-644.

Harciarek, M., \& Jodzio, K. (2005). Neuropsychological differences between frontotemporal dementia and Alzheimer's disease: A review. Neuropsychology Review, 15(3), 131-145.

Hodges, J. R., \& Patterson, K. (2007). Semantic dementia: A unique clinicopathological syndrome. Lancet Neurology, 6(11), 1004-1014.

Hutchinson, A. D., \& Mathias, J. L. (2007). Neuropsychological deficits in frontotemporal dementia and Alzheimer's disease: A meta-analytic review. Journal of Neurology Neurosurgery and Psychiatry, 78(9), 917-928.

James, M., \& Warrington, E. K. (1991). The visual object and space perception battery. Suffolk, UK: Thames Valley Test Company.

Keane, J., Calder, A. J., Hodges, J. R., \& Young, A. W. (2002). Face and emotion processing in frontal variant frontotemporal dementia. Neuropsychologia, 40(6), $655-665$.
Kertesz, A., Davidson, W., \& Fox, H. (1997). Frontal behavioral inventory: Diagnostic criteria for frontal lobe dementia. Canadian Journal of Neurological Sciences, 24(1), 29-36.

Kipps, C. M., \& Hodges, J. R. (2006). Theory of mind in frontotemporal dementia. Social Neuroscience, 1(3-4), 235-244.

Lavenu, I., \& Pasquier, F. (2005). Perception of emotion on faces in frontotemporal dementia and Alzheimer's disease: A longitudinal study. Dementia and Geriatric Cognitive Disorders, 19(1), 37-41.

Lavenu, I., Pasquier, F., Lebert, F., Petit, H., \& Van der Linden, M. (1999). Perception of emotion in frontotemporal dementia and Alzheimer disease. Alzheimer Disease E' Associated Disorders, 13(2), 96-101.

Lieberman, M. D. (2007). Social cognitive neuroscience: A review of core processes. Annual Review of Psychology, 58, 259-279.

Lough, S., Kipps, C. M., Treise, C., Watson, P., Blair, J. R., \& Hodges, J. R. (2006). Social reasoning, emotion and empathy in frontotemporal dementia. Neuropsychologia, 44(6), 950-958.

Luzzatti, C., Willmes, K., De Bleser, R., Bianchi, A., Chiesa, G., De Tanti, A., et al. (1994). Nuovi dati normativi per la versione italiana dell'Aachener Aphasia test. Archivio di Psicologia, Neurologia e Psichiatria, 55, 1086-1131.

McKhann, G. M., Albert, M. S., Grossman, M., Miller, B., Dickson, D., \& Trojanowski, J. Q. (2001). Clinical and pathological diagnosis of frontotemporal dementia: Report of the work group on frontotemporal dementia and Pick's disease. Archives of Neurology, 58(11), 1803-1809.

Miceli, G., Laudanna, A., Burani, C., \& Capasso, R. (1994). Batteria per l'analisi deideficit afasici: BADA. Milano: CEPSAG - Univeristà Cattolica del Sacro Cuore.

Neary, D., Snowden, J. S., Gustafson, L., Passant, U., Stuss, D., Black, S., et al. (1998). Frontotemporal lobar degeneration: A consensus on clinical diagnostic criteria. Neurology, 51(6), 1546-1554.

Patterson, K., Nestor, P. J., \& Rogers, T. T. (2007). Where do you know what you know? The representation of semantic knowledge in the human brain. Nature Reviews Neuroscience, 8(12), 976-987.

Perry, R. J., \& Hodges, J. R. (2000). Differentiating frontal and temporal variant frontotemporal dementia from Alzheimer's disease. Neurology, 54(12), 2277-2284.

Premack, D. G., \& Woodruff, G. (1978). Does the chimpanzee have a theory of mind? Behavioral and Brain Sciences, 1, 515-526.

Rankin, K. P., Gorno-Tempini, M. L., Allison, S. C., Stanley, C. M., Glenn, S., Weiner, M. W., et al. (2006). Structural anatomy of empathy in neurodegenerative disease. Brain, 129(Pt 11), 2945-2956.

Rankin, K. P., Kramer, J. H., \& Miller, B. L. (2005). Patterns of cognitive and emotional empathy in frontotemporal lobar degeneration. Cognitive and Behavioural Neurology, 18(1), 28-36.

Rankin, K. P., Kramer, J. H., Mychack, P., \& Miller, B. L. (2003). Double dissociation of social functioning in frontotemporal dementia. Neurology, 60(2), 266-271.

Rizzo, S., Venneri, A., \& Papagno, C. (2002). Famous face recognition and naming test: A normative study. Neurological Science, 23(4), 153-159.

Rosen, H. J., Pace-Savitsky, K., Perry, R. J., Kramer, J. H., Miller, B. L., \& Levenson, R. W. (2004). Recognition of emotion in the frontal and temporal variants of frontotemporal dementia. Dementia and Geriatric Cognitive Disorders, 17(4), 277-281.

Rosen, H. J., Perry, R. J., Murphy, J., Kramer, J. H., Mychack, P., Schuff, N., et al. (2002) Emotion comprehension in the temporal variant of frontotemporal dementia. Brain, 125(Pt 10), 2286-2295.

Rosen, H. J., Wilson, M. R., Schauer, G. F., Allison, S., Gorno-Tempini, M. L., PaceSavitsky, C., et al. (2006). Neuroanatomical correlates of impaired recognition of emotion in dementia. Neuropsychologia, 44(3), 365-373.

Singer, T. (2006). The neuronal basis and ontogeny of empathy and mind reading: Review of literature and implications for future research. Neuroscience and Biobehavioral Reviews, 30, 855-863.

Snowden, J. S., Goulding, P. J., \& Neary, D. (1989). Semantic dementia: a form of circumscribed cerebral atrophy. Behavioural Neurology, 2, 167-182.

Sullivan, S., \& Ruffman, T. (2004). Emotion recognition deficits in the elderly. International Journal of Neuroscience, 114(3), 403-432.

Viskontas, I. V., Possin, K. L., \& Miller, B. L. (2007). Symptoms of frontotemporal dementia provide insights into orbitofrontal cortex function and social behavior. Annals of the New York Academy of Sciences, 1121, 528-545.

Werner, K. H., Roberts, N. A., Rosen, H. J., Dean, D. L., Kramer, J. H., Weiner, M. W., et al. (2007). Emotional reactivity and emotion recognition in frontotemporal lobar degeneration. Neurology, 69(2), 148-155.

Wiggins, J. S. (1995). Interpersonal adjective scale. Professional manual. Odellla, FL: Psychological Assessment Resources.

Wittenberg, D., Possin, K. L., Rascovsky, K., Rankin, K. P., Miller, B. L., \& Kramer, J. H. (2008). The early neuropsychological and behavioral characteristics of frontotemporal dementia. Neuropsychology Review, 18(1), 91-102.

Young, A., Perrett, D., Calder, A., Sprengelmeyer, R., \& Ekman, P. (2002). Facial expressions of emotion - Stimuli and tests (FEEST). Bury St Edmunds, England: Thames Valley Test Company. 